\title{
Increase in cervical cancer mortality in Spain, 1951-1991
}

\author{
Javier Llorca, M Dolores Prieto, Miguel Delgado-Rodríguez
}

\begin{abstract}
Background-The trend in cervical cancer mortality in Spain from 1951 to 1991 is examined.

Methods-Analysis of national mortality statistics calculating age standardised mortality rates and an age-period cohort analysis. A fit to the Gompertz function was made to estimate the influence of the environmental factors on the mortality rates evolution.

Main results-The age standardised mortality rate in Spain is lower than in other developed countries (USA or Estonia) and equal to Norwegian and Finland rates; but whereas in these countries the trend is to decrease, the Spanish rate has increased during this period, because of a cohort effect. A misclassification bias could be responsible for the trend in women aged 40 and older but the increasing trend in younger women could not be interpreted as espurious. The Gompertzian analysis suggests an increase in environmental factors causing cervical cancer.

Conclusions-Cervical cancer mortality rates are increasing in Spain because of environmental factors.
\end{abstract}

(F Epidemiol Community Health 1999;53:408-411)

Cervical cancer mortality has been decreasing in developed countries for several decades. ${ }^{1-6}$ This decrease is attributable to, at least in part, a widespread use of screening and early treatment. We analyse the mortality data of cervical cancer in Spain from 1951 to 1991 using a graphical approach to delineate age, period, and cohort effects, and the Gompertz function. The Gompertz analysis has its utility in measuring changes in competitive, genetic, and environmental factors influencing mortality rates. It does not allow the identification of changes in specific factors but the generation of hypotheses about them. The purpose of this paper is to identify temporal changes that might possibly be related to variations in environmental or lifestyle factors.

Division of Preventive Medicine and Public Health, School of Medicine, University of Cantabria, Av Cardenal Herrera Oria s/n, 39011-Santander, Spain

Correspondence to: Dr J Llorca.

Accepted for publication 6 July 1998 the direct method using a world standard population. $^{9}$

A difficulty in interpretating cervical cancer mortality trend is a feasible misclassification of causes of death. Sánchez Garrido et al analysed accuracy of death certificates related with uterus cancer in a Spanish province (Girona) between 1985 and $1989 .{ }^{16}$ They found that $24 \%$ of deaths (20 of 85 ) under the rubric "uterus not otherwise specified" were actually cervical cancer. To check out the impact of this misclassification in our results, we carried out a sensitivity analysis on age specific mortality rates: mortality figures in 1961, 1971, 1981, and 1991 under the rubric "uterus not otherwise specified" (UNOS) were obtained. Next, for each age group and for each period 1961-1991, 1971-1991, and 1981-1991, we calculated the percentage of deaths certified as UNOS needed to invert the trend of cervical cancer mortality.

Age-period cohort analysis was made using the surfaces approach by Jolley and Giles. ${ }^{10}$ They use a synoptic method similar to a topographic map with age and calendar time as its ordinates, and display lines named "isothanats" connecting points of approximately equal interpolated values. To make this analysis we used the Mathematica software version 2.0 for Windows. ${ }^{11}$

Gompertz analysis has been widely used as a descriptor of general and disease specific human mortality. ${ }^{12-14}$ Gompertzian function assumes an exponential relation between age and mortality rates $\left(R_{x}=R_{0} e^{a x}\right)$, where $R_{x}$ is the mortality rate at age $x, R_{0}$ is a theoretical mortality rate at birth, and $e$ is the base of the natural logarithm. This relation can be analysed easily using a logarithmic transformation (equation 1).

$$
L n R_{x}=\alpha x+L n R_{0}
$$

The Gompertzian analysis has two steps: transversal and longitudinal. In transversal analysis, age specific mortality rates at 25 and over and age are fitted using linear regression (equation 1). So a set of lines is obtained (one for each year), each determined by two coeficients: the slope $\alpha$ and the independent term $\operatorname{Ln} R_{0}$. As usual, the independent term is the ordinate value when $x=0$; that is, it is a theoretical mortality at birth. This mortality is actually an extrapolation out the age range used-25 and over-and it cannot, strictly speaking, be considered a mortality rate.

The second step is a longitudinal analysis of the evolution of the lines obtained in the first step. To that end, we study how changes in $\alpha$ are conditioned by changes in $L n R_{0}$. Biological 


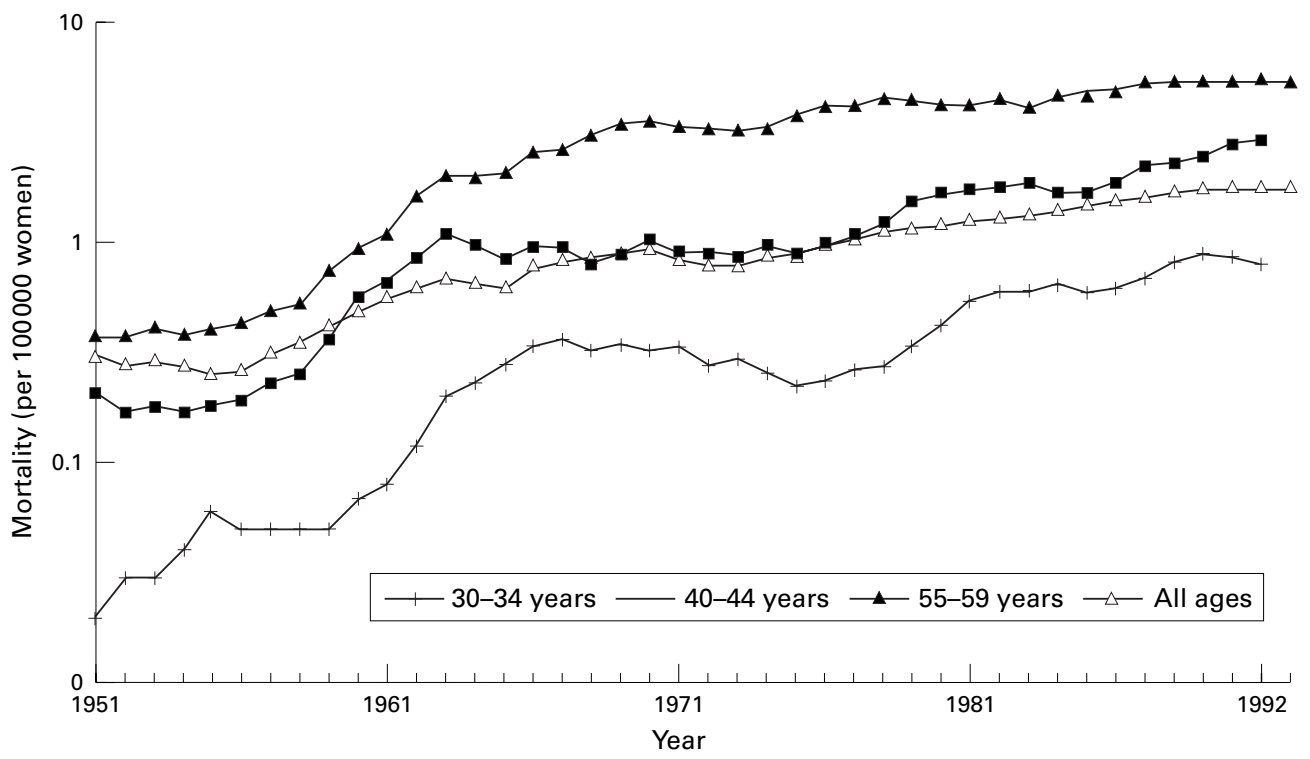

Figure 1 Age adjusted and age specific (for selected age groups) mortality rates. Spain, 1951-1991.

sense of this evolution is given by the StrehlerMildvan modification (equation 2). ${ }^{15}$

$$
B=\frac{\alpha}{\operatorname{Ln}\left(K / R_{0}\right)}
$$

The interpretation of these parameters is: $K$ is an aggregation of the environmental factors influencing cervix uteri mortality. For example, $K$ includes factors such as sexual habits or screening coverage. $K$ can be estimated by sustituying in equation 2 .

$R_{0}$ is the result of two kind of factors: competing mortality risks and age independent environmental factors. For example, a competing mortality risk could be a disease increasing its mortality at early ages but not at late ages; that would cause a decrease in mortality by cervical cancer at early ages. On the other hand, a new hypothetical non-curative treatment against cervical cancer applied in earlier ages would decrease mortality rate at these ages but would increase it later.

Finally, $B$ is the aggregation of genetic factors influencing cervical cancer mortality. It can be considered constant for a short period of time. In each year $N$ let us consider $B_{N}$ as the change of $\alpha$ as a function of the change in $\operatorname{Ln} R_{0}$ (equation 3). Then $B$ can be estimated as the median of $B_{N}{ }^{13}$ In a previous report we have pointed out the mathematical drawbacks of this procedure. $^{14}$

$$
B_{N}=\frac{\alpha_{N+1}-\alpha_{N}}{\operatorname{LnR}_{0(N)}-\operatorname{LnR}_{0(N+1)}}
$$

The Gompertzian analysis was restricted to the period 1961-1991. From 1951 to 1960 the SNIS gave its data in wide age groups stratifying people aged 65 and over, whereas from 1961 on it offered five year strata.

\section{Results}

Figure 1 shows the evolution of age adjusted and age specific (for selected age groups) mortality rates from 1951 to 1991 . Age adjusted mortality has increased from 0.32 in 1951 to 1.69 deaths per 100000 women. The slope was almost constant from 1962 to 1991 therefore a constant increase rate has occurred; however from 1951 to 1961 the trend was irregular and with a greater slope. Simular shapes can be shown for age specific mortality rates.

Table 1 shows the results of the sensitivity analysis. If the percentage of misclassification described by Sánchez Garrido et al (24\%) could be extended to all the period analysed here, it can modify the trend (from increase to decrease) in 40-69 year old women, but a much larger misclassification ( $50 \%$ and over) is necessary to explain the increase in 25-39 year old women mortality rates.

To make an age, period, and cohort analysis we perform a three dimensional graph with the age at death as the $\mathrm{x}$ axis, the calendar year as the $y$ axis, and the mortality rate as the $\mathrm{z}$ axis. Mortality rate presents a trend to increase with calendar year and age in this figure (not shown).

Figure 2 displays a projection of this three dimensional graph on the $x y$ plane. To interpretate the figure, the clearer the grey scale the higher the mortality rate; the isothanats are the limit lines between two levels of grey, and the

Table 1 Sensitivity analysis for misclassification bias of cause of death. Figures show the cut point (in percentages) of deaths certified as "uterus otherwise not classified" needed to invert the trend of cervical cancer mortality

\begin{tabular}{llcc}
\hline \multirow{4}{*}{ Age } & \multicolumn{2}{l}{ Period } & \\
\cline { 2 - 4 } & $1961-1991$ & $1971-1991$ & $1981-1991$ \\
\hline $25-29$ & 51 & 26 & 56 \\
$30-34$ & 72 & 47 & 75 \\
$35-39$ & 47 & 105 & 295 \\
$40-44$ & 14 & 29 & -3 \\
$45-49$ & 11 & 19 & 25 \\
$50-54$ & 11 & 13 & 28 \\
$55-59$ & 16 & 9 & 24 \\
$60-64$ & 15 & 10 & 3 \\
$65-69$ & 19 & 17 & 2 \\
$70-75$ & 26 & 21 & 60 \\
$75-79$ & & 20 & 24 \\
$80-84$ & & 19 & 13 \\
85 and over & & 10 & -6 \\
\hline
\end{tabular}




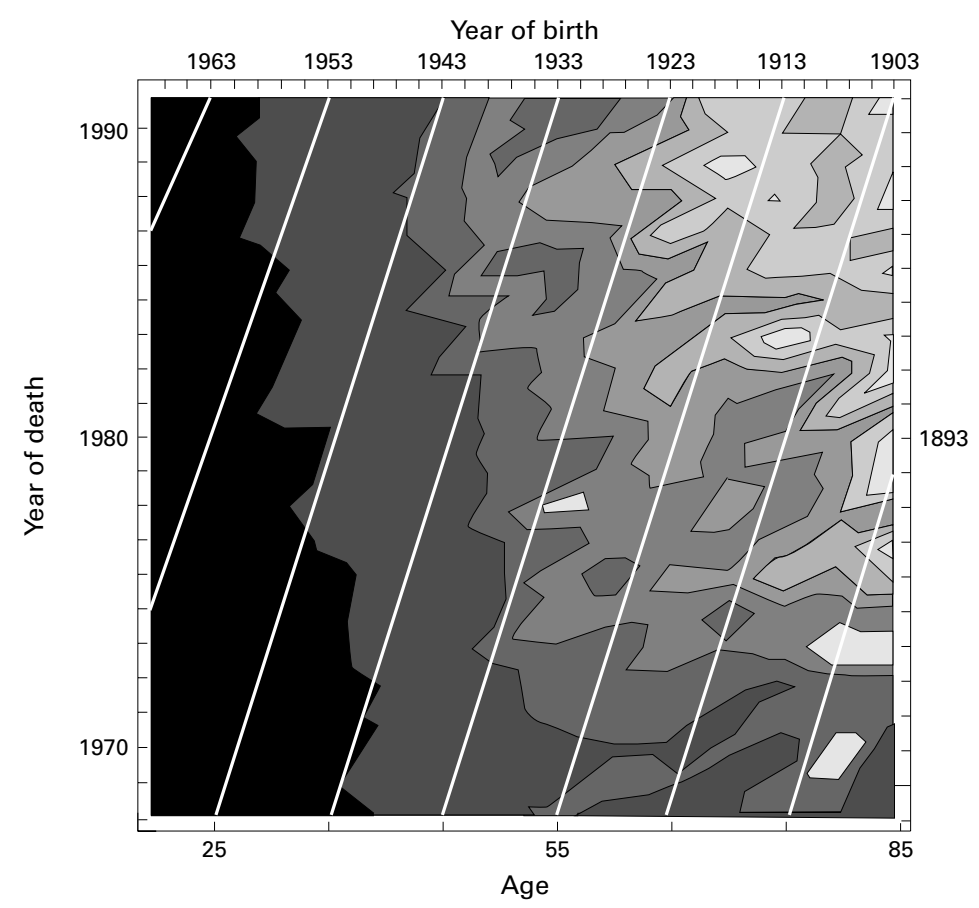

Figure 2 Mortality rates by age at death ( $x$ axis) and year of death (y axis), Spain, 1971-1991. The more grey level, the more mortality rate. Solid black lines connect point with equal mortality rate. Birth cohorts are indicated by oblique white lines.

oblique white lines are the birth cohorts. The isothanats deviate toward decreasing age when calendar year increases. This is interpreted as an increase in mortality. Finally, the evolution of the mortality at equal age can be seen going vertically from the bottom to the top: the later birth cohorts are associated with a higher mortality; for example, let us consider mortality rates at 55 years: if we go over a vertical line with abscissa $=55$, we cross different levels of grey from darker (in 1970) to clearer (in 1990), showing higher rates. To study if one period

Table 2 Cervical cancer mortality, Spain, 1961-1991. Gompertzian analysis

\begin{tabular}{llllll}
\hline Year & Ln $R_{0}$ & $a$ & $r$ & $p<$ & Ln $K$ \\
\hline 61 & -3.4084 & 0.0616 & 0.86 & 0.001 & 3.67 \\
62 & -3.4608 & 0.0641 & 0.83 & 0.01 & 3.91 \\
63 & -3.4895 & 0.0637 & 0.87 & 0.001 & 3.83 \\
64 & -2.7941 & 0.0558 & 0.82 & 0.01 & 3.62 \\
65 & -2.4586 & 0.0501 & 0.83 & 0.01 & 3.30 \\
66 & -3.7253 & 0.0630 & 0.86 & 0.001 & 3.51 \\
67 & -3.1247 & 0.0579 & 0.90 & 0.001 & 3.52 \\
68 & -3.3985 & 0.0746 & 0.90 & 0.001 & 5.18 \\
69 & -3.3802 & 0.0717 & 0.89 & 0.001 & 4.86 \\
70 & -3.6691 & 0.0733 & 0.92 & 0.001 & 4.76 \\
71 & -2.8898 & 0.0542 & 0.89 & 0.001 & 3.34 \\
72 & -1.6112 & 0.0297 & 0.44 & $N S$ & 1.80 \\
73 & -2.9880 & 0.0535 & 0.82 & 0.001 & 3.16 \\
74 & -3.0876 & 0.0583 & 0.85 & 0.001 & 3.61 \\
75 & -2.8359 & 0.0548 & 0.88 & 0.001 & 3.47 \\
76 & -3.1208 & 0.0635 & 0.90 & 0.001 & 4.17 \\
77 & -2.8835 & 0.0589 & 0.87 & 0.001 & 3.89 \\
78 & -2.8891 & 0.0620 & 0.92 & 0.001 & 4.23 \\
79 & -3.0327 & 0.0646 & 0.92 & 0.001 & 4.39 \\
80 & -2.4630 & 0.0552 & 0.86 & 0.001 & 3.88 \\
81 & -2.6208 & 0.0587 & 0.88 & 0.001 & 4.13 \\
82 & -2.5532 & 0.0575 & 0.92 & 0.001 & 4.05 \\
83 & -2.4483 & 0.0564 & 0.85 & 0.001 & 4.04 \\
84 & -2.5229 & 0.0587 & 0.88 & 0.001 & 4.23 \\
85 & -2.9568 & 0.0667 & 0.88 & 0.001 & 4.71 \\
86 & -1.9941 & 0.0510 & 0.88 & 0.001 & 3.87 \\
87 & -2.4836 & 0.0599 & 0.89 & 0.001 & 4.40 \\
88 & -1.8506 & 0.0511 & 0.83 & 0.001 & 4.02 \\
89 & -2.0552 & 0.0550 & 0.88 & 0.001 & 4.27 \\
90 & -2.3771 & 0.0599 & 0.83 & 0.001 & 4.51 \\
91 & -1.8724 & 0.0517 & 0.84 & 0.001 & 4.07 \\
\hline & & & & &
\end{tabular}

effect is present, for example in 1980, go over a horizontal line with ordenate 1980 . If one period effect is present, all, or almost all, isothanats could show a simultaneous change of direction. Such effect is not apparent in figure 2 .

Table 2 shows the coefficients of the Gompertz function for every year: $\alpha, \operatorname{Ln} R_{0}$ and $r$ (linear correlation coefficient). Except for 1972 ( $r=0.44 ; \mathrm{p}>0.05), r$ was between 0.82 and 0.92 ( $\mathrm{p}<0.05$ for all cases). $B$ is obtained from equation IV, $(0.0173$, 95\% CI: 0.0162, $0.0194)$. Evolution of $L n K$, calculated with this value of $B$, is presented in table 2: an increase from values lower than 4 in the 1960 decade to values greater than 4 in 1980 decade can be appreciated. An anomalous behaviour for 1968-70 can be attributed to a change in the International Classification of Diseases (from 7th to 8th revision): for example, mortality rate increases from 2.2 per 100000 women aged 65-69 in 1967 to 5.2 in 1968, and returns to 2.4 in 1971 .

\section{Discussion}

Age adjusted mortality attributable to cervical cancer in Spain is increasing at least from 1951, whereas in other developed countries the opposite has been observed. ${ }^{12}$ For example, USA mortality has decreased by about $73 \%$ since 1950. Despite these trends, the mortality rate in Spain is lower than in USA (2.9 deaths per 100000 white women and 7.6 deaths per 100000 black women $)^{3}$ and some Nordic countries (3.8 per 100000 in Estonia), ${ }^{4}$ but it is similar to Norwegian rates (1.4 per 100000 in 1991 after an important decrease from 6.6 per 100000 in 1960) ${ }^{6}$ and Finnish rates (1.6 per 100 000). ${ }^{4}$

A misclassification rate of cause of death lower than $24 \%$ could explain trend in women aged 40 and over (24\% in table 1). Nevertheless, this explanation does not explain the trend observed in younger women for the whole period, as misclassification should be higher than $50 \%$, and almost impossible for the 1981-1991 period, as it should be greater than $200 \%$.

To analyse the causes of this increase an ageperiod cohort analysis was made. If a period effect is present, all the isothanats must change in the same way at the same ordinate. This effect is not appreciated in the figure 2 and a period effect can be discarded. The increase in the mortality rates is common to all cohorts, so the main effect in this increase is a cohort one.

The increase in $L n K$ by the Gompertzian longitudinal analysis means that changes in mortality can be attributed to environmental changes.

The interpretation of the trend in cervical cancer mortality is more difficult than in other cancers because there are several factors influencing incidence and mortality. These factors include changes in sexual habits, oral contraceptive use, tobacco smoking, sexually transmitted diseases (papillomavirus), changes in case-fatality rates, and extension and distribution of screening. ${ }^{1}{ }^{217-19}$

Cervical cancer mortality rate in Spain was very low from 1951 to 1970 . Until 1960 official statistics ${ }^{7}$ included data from wide age groups, 
therefore age adjusted mortality until this year cannot adequately control for age; probably, this is the main reason of the first increase for all age groups.

Low rates until 1975 can be attributable to dominant sexual habits (late initiation of sexual intercourse, one partner only, late introduction of hormonal contraception, inclusion, until 1976, of adultery in penal laws, etc). From 1975 and with the establishment of democracy great social changes were observed, including modifications in sexual habits, probably accompanied by an increase in papillomavirus transmission. Young women are more sensible to these changes. Indirect data support this hypothesis; for example an association between cervix uteri mortality rates and oral contraceptives use. ${ }^{20}$ Because of the large latency period of cervical cancer, these factors could increase the cervical cancer incidence in posterior decades.

Ecological studies show a decrease in cervical cancer mortality from 1950 onwards in countries with well organised screening programmes. ${ }^{19}{ }^{21-23}$ In Spain, a screening programme with Papanicolau smear by the National Health Service was started in the mid-1970s and offered by family planning clinics. This programme did not reach an important proportion, between $30 \%$ and $46 \%$, of sexually active women until the mid-1980s. ${ }^{24-26}$ Furthermore, women attending a first screening do not continue in the programme. ${ }^{24}$ Coverage and frequency of screening is higher in young women. ${ }^{24-26}$ Any positive effect of this programme is unlikely to be appreciated before 1990 .

One of the goals of the Gompertzian longitudinal analysis is to differentiate between genetic and environmental factors influencing the disease. In this paper, we have found that genetic factors $(B)$ have remained almost constant and environmental factors $(\operatorname{Ln} K)$ are responsible for the increase in mortality. Riggs, in his study on cervical cancer in USA, ${ }^{13}$ found a decrease in $\operatorname{Ln} K$, and attributed it to environmental factors.

Ten year survival rates of invasive cervical cancer have increased from $33 \%$ to $55 \%{ }^{27}$; therefore, the increase in mortality suggests a greater increase in the incidence of invasive cervical cancer. This hypothesis cannot be proved because the population-based registries of cancer in Spain do not have data before 1978 (except in some local registries) ${ }^{28}$ However, the oldest local registries provide some evidence in this sense: an increase has been observed in the incidence of invasive cervical cancer from 3.72 per 100000 in $1973-1977$ to 4.97 in $1988-$ 1989 in Navarra ${ }^{29}$ and from 8.2 per 100000 in $1980-1983$ to 9.5 in $1988-1992$ in Tarragona. ${ }^{30}$

In conclusion, the mortality rate of cervical cancer is increasing in Spanish young women because of a cohort effect mediated by environmental factors; a similar trend in older women could be explained by a misclassification of causes of death. An inversion of the trend is not foreseeable until the screening programmes cover a greater proportion of the women at risk.

1 Cuzick J, Boyle P. Trends in cervix cancer mortality. Cancer Surv 1988;7:417-39.
KEY POINTS

- The cervical cancer mortality rate in Spain is increasing, mainly because of a cohort effect.

- Environmental factors like changes in sexual behaviours might be the main cause of this increase.

- The impact of a screening programme is unlikely to be appreciated before 1990 .

2 Beral V, Hermon C, Munoz N, et al. Cervical cancer. Cancer Surv 1994; 19/20:265-85.

3 Black-White differences in cervical cancer mortality. U.S. 1980-1987. MMWR 1990;39:245-8.

4 Aareleid t, Pukkala E, Thomson H, et al. Cervical cancer incidence and mortality trends in Finland and Estonia: a screened vs. an unscreened population. Eur f Cancer 1993; 29A:745-9.

5 Sasieni P, Cuzick J, Farmery E. Accelerated decline in cervical cancer mortality in England and Wales. [Letter]. Lancet 1995;346:1566-7.

6 Nieminen P, Kallio M, Hakama M. The effect of mass screening in incidence and mortality of squamous and adenocarcinoma of cervix uteri. Obstet Gynecol 1995;85: $1017-21$.

7 Movimiento Natural de la Población Española. Madrid: Instituto Nacional de Estadística, 1951-1991.

8 Censo de la Población Española. Madrid: Instituto Nacional de Estadística, 1950, 1960, 1970, 1981, 1991.

9 Waterhouse J, ed. Cancer incidence in five continents. Lyon: IARC, 1976:456.

10 Jolley D, Giles GG. Visualizing age-period-cohort trend surfaces: a synoptic approach. Int $\mathcal{F}$ Epidemiol 1992;21:17882.

11 Wolfram S. Mathematica: a system for doing mathematics by computer. Reading, MA: Addison-Wesley Publishing Company, 1991 .

12 Riggs JE. Longitudinal Gompertzian analysis of adult mortality in the US, 1900-1986. Mech Ageing Dev 1990; tality in the

13 Riggs JE. Longitudinal Gompertzian analysis of cervical cancer mortality in the U.S., 1962-1987: A method of quantitatively demonstrating changing environmental influences upon deterministic mortality dynamics. Mech Ageing Dev 1992; 63:117-29.

14 Prieto D, Llorca J, Delgado-Rodríguez M. Longitudinal Gompertzian and Weibull analyses of adult mortality in Spain (Europe), 1900-1992. Mech Ageing Dev 1996;90:3551 .

15 Strehler BL, Mildvan AS. General theory of mortality and aging. Science 1960;132:14-21.

16 Sánchez Garrido MV, Izquierdo A, Beltrán $\mathrm{M}$, et al. Tendencias temporales de la mortalidad por cáncer de cérvix en Cataluña 1975-1992: Análisis del Boletín Estadístico de Defunción y del Registro de Cáncer de Girona. Gac Sanit 1996;10:67-72.

17 Knox EG. Cancer of the uterine cervix. In: Magnus K, ed. Trends in cancer incidence: causes and practical implications. London: Hemisphere Publishing, 1982:271-7.

18 Holman CD, Armstrong BK. Cervical cancer mortality trends in Australia- an update. Med f Aust 1987;146:410-12.

19 Anderson GH, Boyes DA, Benedet JL, et al. Organization and results of the cervical cytology screening programme in British Columbia, 1955-85. BMF 1988;296:975-8.

20 Vioque J, Fenollar J. La distribución de la mortalidad por cáncer cervical en España (1981-1986). Med Clin (Barc) 1995;104:287-92.

21 Laara E, Day N, Hakama M. Trends in mortality from cervical cancer in Nordic countries: Association with organised screening programmes. Lancet 1987;i:1247-9.

2 Eddy DM. Screening for cervical cancer. Ann Intern Med 1990;113:214-26.

23 Devesa SS, Silverman DT, Young JL, et al. Cancer incidence and mortality trends among whites in the United States, and mortality trends among whites in the Unit

24 Izquierdo A, Viladin P, Borrás JM, et al. Percepción de las causas de cáncer y su prevención en mujeres de Girona. causas de cáncer y su prevención
Med Clin (Barc) 1996;107:14-19.

25 Olazábal Ulacia JC, Montero Luengo J, Pastor Mateos F, et al. Diez años de citologías de cérvix uterino en un Centro de Salud. Aten Primaria 1997;20:293-8

26 Borrell C, Pasarín I, Plasència A. Enquesta de salut de Barcelona 1992-1993. Barcelona: Ajuntament de Barcelona, 1995.

27 Sparen P, Gustafsson L, Friberg LG, et al. Improved control of invasive cervical cancer in Sweden over six decades by earlier clinical detection and better treatment. $\mathcal{F}$ Clin Oncol 1995;13:715-25.

28 Cáncer en España. Madrid: Ministerio de Sanidad y Consumo, 1993.

29 Servicio de Planificación y Ordenación Sanitaria y Grupo Técnico de Trabajo sobre cáncer de cuello de útero. Detección precoz del cáncer de cuello de útero. Pamplona: Gobierno de Navarra, 1995.

30 Borràs JM, Borràs J, Vilaiu $\mathrm{P}$, et al. Epidemiología y prevención del cáncer en Catalnya, 1975-1992. Barcelona: Institut Català d'Oncologia, 1997 . 